\title{
An Integrated Single-Stage Converter fed Sensor-less Motor Drive
}

\author{
V. Aishwarya, K. Gnana Sheela
}

\begin{abstract}
This paper details an Integrated Single-stage converter fed sensor-less BLDC motor drive. The drive speed is regulated by altering the $D C$ voltage of the inverter that drives the motor. The switches of the inverter are operated at the line frequency, thereby reducing the inverter switching stresses and enhancing the overall drive system efficiency. The converter works in Dual-discontinuous Current Mode (D-DCM) for Power Factor Correction (PFC) and better power quality at the supply mains. DC voltage control is used adjust the duty ratio of the converter switch. Fast voltage regulation, zero current switching at turn-on and enhanced power factor for a broad range of speeds are the advantages of this converter configuration. The necessity of Hall-Effect position sensors is eliminated by employing a sensor-less technique for brushless dc motor commutation. This reduces the dimensions, volume and expenditure of the motor drive and upgrades its overall efficiency. Drive performance is assessed over an extensive span of speeds. A power factor approximating to unity, and enhanced power quality indicators which are adequately within the sanctioned cap of IEC standard 61000-3-2 are obtained.
\end{abstract}

Index Terms: BLDC motor, Integrated Single-Stage Converter, Voltage Source Inverter, Digital Commutation, Voltage Mode Control, Dual-Discontinuous Conduction Mode

\section{INTRODUCTION}

Sensor-less BLDC motor drives are largely employed in low-power, low-cost applications owing to features like faster dynamic response, high ruggedness, high power density, extended running life, enhanced efficiency, silent operation, exalted torque-to-weight ratio, broader speed ranges [1,2]. These motors have no brushes in them, and current commutation in the windings is implemented electronically based on feedback of the rotor position. Thus, they include sensors to detect the exact rotor position. This escalates the price and motor dimensions and minimizes its sturdiness [2]. Economization of variable-frequency drives is possible through two methods, which includes topological method and control method. The first approach aims at minimalistic utilization of switches in the power circuit whereas, the later approach aims at designing \& implementing new control strategies for securing the desired dynamics [2,3].

Revised Manuscript Received on 30 July 2019.

* Correspondence Author

V. Aishwarya*, EEE Department, Toc H Institute of Science \& Technology, Ernakulam, India.

Dr. K. Gnana Sheela, ECE Department, Toc H Institute of Science \& Technology, Ernakulam, India.

(C) The Authors. Published by Blue Eyes Intelligence Engineering and Sciences Publication (BEIESP). This is an open access article under the CC-BY-NC-ND license http://creativecommons.org/licenses/by-nc-nd/4.0/
Thus, several sensor-less control techniques for enhancing the performance of these drives like Back-EMF zero-crossing detection, Varying inductance approach, Flux-linkage variation, MRAS control, Extended Kalman Filter method etc. have been described in [2,4-9].

Compared to multi-stage drives, an Integrated Buck-boost Buck converter is a single-stage converter employing a single switch, which offers advantages like reduced switching losses, improved dynamic performance, power factor correction, improved power quality, fast voltage regulation, and Zero-Current switching(ZCS) at Turn-ON for reduced losses at the switch[1].The PFC converters generally have two operational modes: (i) Continuous Conduction Mode (CCM) (ii) Discontinuous Conduction Mode (DCM). CCM offers continuous current through the inductor, reduced stress on the converter switch, at a higher sensor count [20]. This mode is generally employed in large power applications. DCM offers discontinuous inductor current and demands a unit sensor for sensing the voltage of the DC-bus [25]. Here, the switching stress rises, and is restrained to lower power appliances [16-20].The losses in the inverter switches during conduction are minimized by triggering the inverter switches at the line frequency for commutating the motor. The converter functions in the Dual-discontinuous Conduction Mode (D-DCM) [18]. This necessitates a unit sensor for both control of speed and PFC at the AC supply mains [26]. Drive speed is regulated by employing Voltage Mode Control. Sensor-less control is realized using Direct Back-EMF Zero crossing detection technique [24]. This work investigates the various analyses of the Integrated Single-stage converter fed Sensor-less motor drive.

\section{SYSTEM CONFIGURATION}

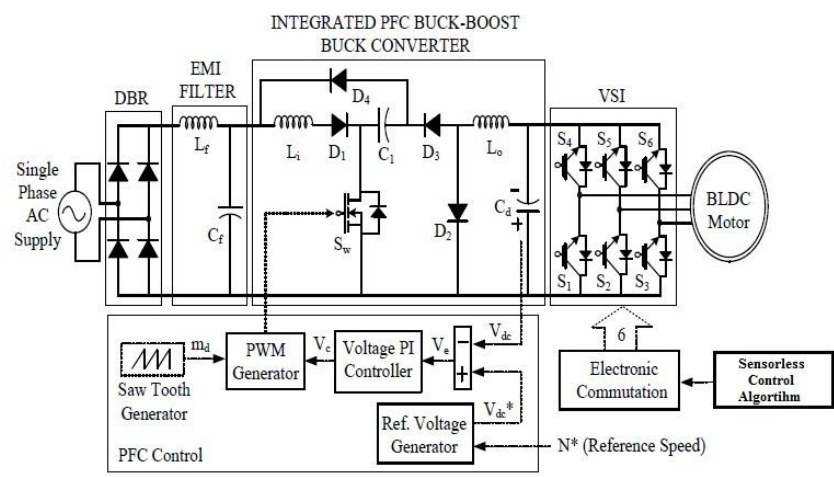

Fig.1. Integrated single-stage converter fed motor drive The drive incorporates a power circuitry, BLDC motor and a controlling unit. The power circuitry is constructed using a full-bridge diode-rectifier, an EMI filter and the Integrated single-stage converter. 
This Integrated converter is a combination of a simple Buck-boost converter and a Buck converter [1]. This converter is cascaded to the output of a rectifier to yield a controlled dc output voltage as seen in Fig. 1 [2].

A low-pass filter following the bridge rectifier eliminates the ripples and EMI issues. Voltage Mode Control is utilized for converter control.Voltage control and power factor correction are obtained by working the converter in D-DCM. The inverter switches are triggered at the line frequency for accomplishing commutation of the motor digitally, and help in the minimization of switching losses and improved efficiency of the VSI [18]. Sensor-less Direct Back-EMF Zero-Crossing detection technique has been used for the digital commutation of the motor [18, 24]. Here, the triggering patterns are developed from three Back-EMFs of the motor phases. This control scheme does not require any sensor to identify the rotor position each 60 electrical degrees \& thus helps in cost-reduction of the drive system [17].

\section{OPERATION OF THE CONVERTER}

This section explains the working of the converter in D-DCM. It operates in a manner that the current in the input inductor, $L_{i}$ and output inductor, $L_{o}$ become discontinuous in a switching period [27]. Figs. 2(a)-(d) show the four modes of the converter in one cycle of switching and, Fig. 2(e) illustrates the related waveforms [1,17].Mode I: When the switch $S_{w}$ is triggered $\mathrm{ON}$, the input inductor $\mathrm{Li}$ starts charging through the switch and diode $D_{1}[17]$. The current $i_{L i}$ increases, with the rate of increase depending upon the instantaneous voltage applied. Capacitor $C_{1}$ charges via the switch, $L_{o}$, \& diode $D_{3}$ to charge the coupling capacitor $C_{d}$ as in Fig. 2(a). Diodes $D_{2}$ and $D_{4}$ remain reverse biased in this mode. In this mode, Currents $i_{L \mathrm{i}}$ and $i_{L o}$ increase while voltage $V_{C 1}$ decreases [18].Mode II: When switch, $S_{w}$ is switched OFF, inductors, $L_{i}$ and $L o$ discharges to charge the capacitors $C_{1}$ and $C_{d}$ as seen in Fig. 2(b). D3 remains reverse biased, while $D_{1}, D_{2}$ and $D_{4}$ conduct for achieving a closed loop for energy transfer between the inductors and capacitors [1]. $V_{C 1}$ starts increasing till the reserved energy in the input inductor, $L_{i}$ becomes zero. Finally, $i_{L i}$ reaches zero and enters the DCM mode, while still some energy is left in $L_{o}$ due to its higher value of time constant, as in Fig. 2(e) [1].Mode III: Switch $S_{w}$ stays in OFF state. The source does not supply any energy to the converter in this mode. $L_{o}$ supplies all of its energy to charge $C_{d}$ as in Fig. 2(c). Hence, $V_{d c}$ continues to increase. $V_{C 1}$ remains constant in this mode. Finally, $L_{o}$ is completely discharged and $i_{\text {Lo }}$ becomes zero. Mode IV: In this operational mode, no energy remains in the input inductor, $L_{i}$ and output inductor $L_{0}$. Hence, the converter goes into dual DCM operation as in Fig. 2(d) and Fig. 2(e). Coupling capacitor, $C_{d}$ contributes the sufficient energy required to the load and $V_{d c}$ decreases [17]. Capacitor $C_{1}$ remains charged with the highest possible voltage. This mode is completed at this juncture of the switching state, and the complete cycle is repeated for the next switching state.

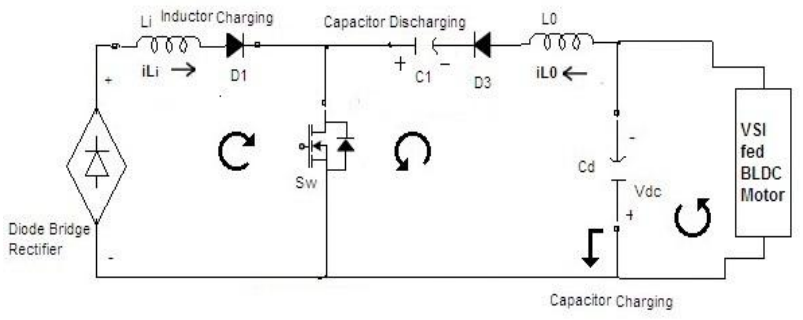

Fig 2a. Mode I

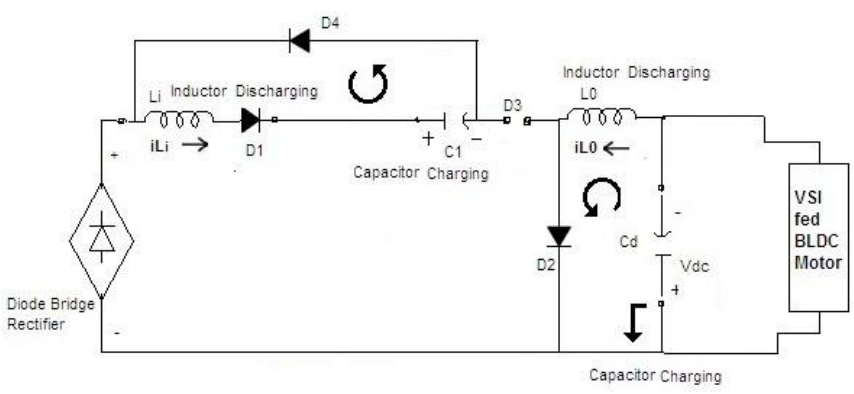

Fig 2b. Mode II

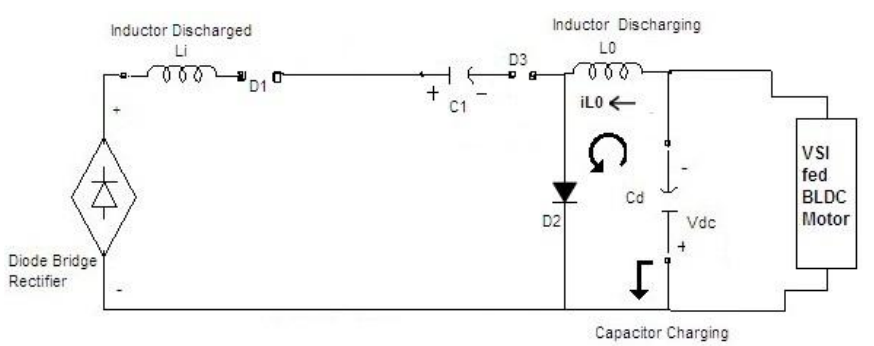

Fig 2c. Mode III

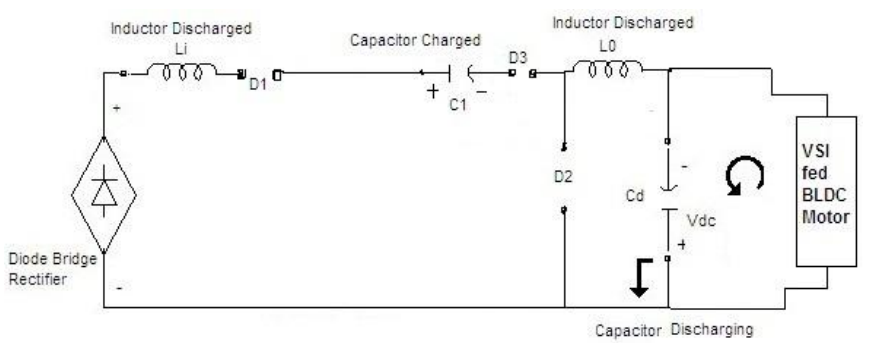

Fig 2d. Mode IV

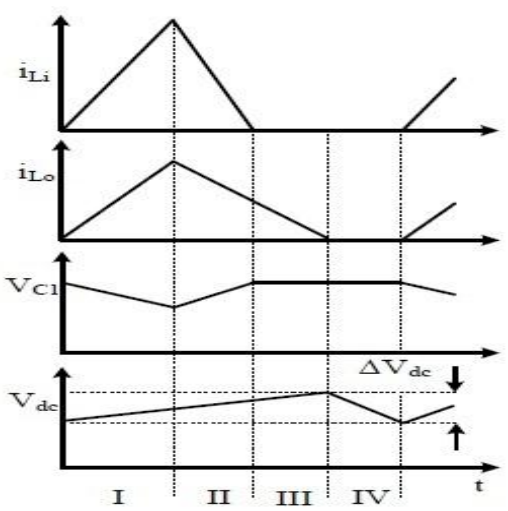

Fig 2e. Waveforms of the converter in D-DCM [1] 


\section{SYSTEM CONTROL}

System Control can be divided into two parts: (i) Converter control to obtain voltage control\& power factor correction. (ii) Digital commutation of motor [1, 20-23].

\section{A. Converter Control}

In this approach of voltage control, a reference voltage $\left(V_{d c}{ }^{*}\right)$ proportional to a desired speed $\left(N^{*}\right)$ is generated by multiplying the desired speed reference with the motor back-EMF constant [21, 22].

$V_{d c}^{*}=k_{v} N^{*}$

Where, $k_{v}$ represents motor voltage constant, $N^{*}$ denotes the desired speed. This proportional voltage is matched with the exact DC voltage to create a voltage error, $V_{e}[21,22]$. Voltage error at a discrete time, ' $t$ ' is given by:

$$
V_{e}(t)=V_{d c}^{*}(t)-V_{d c}(t)
$$

This voltage error is given to a digital controller to develop a digitally-regulated output voltage, $V_{d}$ as $[17,21,22]$ :

$V_{d}(t)=V_{e}(t-1)+k_{p}\left\{V_{e}(t)-V_{e}(t-1)\right\}+k_{i} V_{e}(t)$

where, $k_{p}$ and $k_{i}$ represent the proportional \& integral gain constants respectively. At last, the voltage, $V_{d}$ is modulated using a high frequency carrier waveform to develop gating pulse for the converter switch as:

$m_{d}(t)<V_{d}(t)$, then $S_{w}=1$; else $S_{w}=0$

where, $S_{w}$ denotes the switching pulse for the converter.

\section{B. Digital commutation of motor}

In the conventional sensored control technique, Sensors are needed to identify the rotor's angular position during every $60^{\circ}$ electrical, so as to perform the current commutation of each phase efficiently. These sensors escalate the volume, weight \& price, and decrease the total drive efficiency \& reliability. Here, a sensor-less control strategy is employed, that minimizes the overall bulkiness, volume and price of the drive system. A zero crossing detector (ZCD) is used to sense the instant each time the EMF in the un-energized phase passes through zero [10-13]. At this juncture, the back-EMF can be measured, and it crosses zero[12]. Now, the corresponding phase voltage is equal to the neutral voltage. This point is phase-shifted by $30^{\circ}$ electrical to yield the switching pattern [11-13, 21, 24].

\section{RESULTS AND DISCUSSION}

The drive performance is assessed for several speeds, source voltages and torques on the motor [17]. Motor parameters such as rotor speed $\left(\omega_{m}\right)$, motor torque $\left(T_{e}\right)$, stator current $\left(i_{a}\right)$, back-EMF $\left(E_{b}\right)$ are observed. Converter parameters like DC voltage, inductor currents, and intermediate capacitor voltages are studied to demonstrate the performance of the front-end converter [3, 17]. Power quality indicators like power factor (PF) \& source current harmonic distortion (THD) are assessed. Peak voltage stress and peak current stress of the converter switch is measured [1, 20, 22, 23].

\section{A. Steady State Behaviour of the drive}

Fig. 3 illustrates the performance characteristics of the drive at rated conditions during steady state operation. The supply current in phase-coincidence with the source voltage confirms a power factor of one. Discontinuity in both the inductor currents and continuous conduction of intermediate capacitor voltage demonstrates the converter operation in $\mathrm{D}-\mathrm{DCM}$. Current and voltage stresses in the converter switch is obtained as $22 \mathrm{~A}$ and $800 \mathrm{~V}$ respectively, and are found to be within the acceptable range. A power factor of 0.99 and THD $<5 \%$ is achieved for a wide range of speeds and is found to be within the acceptable limits if IEC61000-3-2.

Fig.4. shows that a Zero Current Switch (ZCS) turn-on phenomenon is obtained, as $V_{S w}$ becomes zero during the turn-on of the converter switch. Hence, the losses in the converter are minimized during switching.

\section{Performance during Supply Voltage Fluctuation}

Fig. 5 illustrates the dynamic behaviour of the drive during a fluctuation of source voltage from $270 \mathrm{~V}$ to $180 \mathrm{~V}$. This demonstrates the behaviour of the drive during practical supply voltage variations.

\section{D.Dynamic Performance of the drive}

Three conditions have been studied so as to understand the behaviour of the drive to the following rapid variations: (i) starting of the drive with increase in dc voltage from $0 \mathrm{~V}$ to $75 \mathrm{~V}$ (ii) dynamic behavior at speed control with a step-rise in dc voltage from $100 \mathrm{~V}$ to $150 \mathrm{~V}$ (iii) Dynamic behaviour of the drive at a step-rise in torque from $0.4 \mathrm{Nm}$ to $0.8 \mathrm{Nm}$. Fig. 6 illustrates the dynamic behaviour at starting with a step-rise in the dc voltage from $0 \mathrm{~V}$ to $75 \mathrm{~V}$; Fig. 7 demonstrates the dynamic behaviour at speed control with a step-rise in the dc voltage from $100 \mathrm{~V}$ to $150 \mathrm{~V}$; Fig. 8 illustrates the dynamic characteristics at a step-increase in load torque from $0.4 \mathrm{Nm}$ to $0.8 \mathrm{Nm}$. A power factor closer to one, and a source current THD $<5 \%$ are obtained. As the dc voltage, $V_{d c}$ is regulated evenly in the entire working range; a sound performance is achieved in this drive. 
Fig. 3. Steady state behaviour of the drive

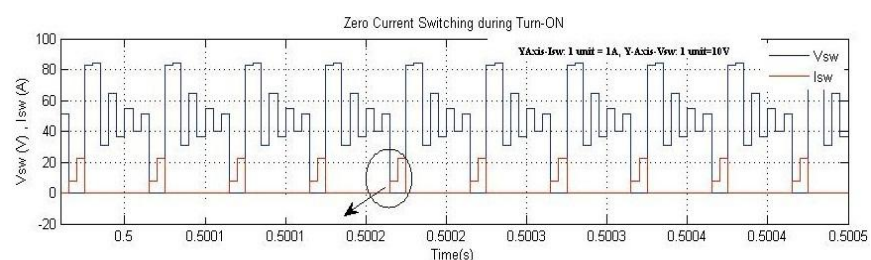

Fig. 4. Zero Current Switching during turn-on

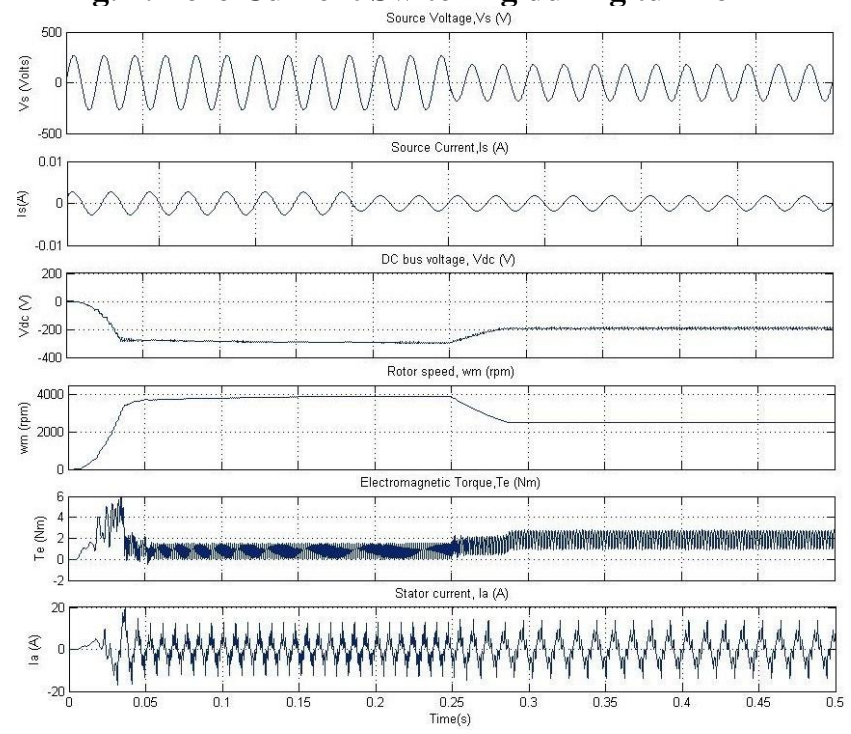

Fig. 5. Dynamic characteristics for a step-fall in supply voltage from $V_{s}=270 \mathrm{~V}$ to $180 \mathrm{~V}$
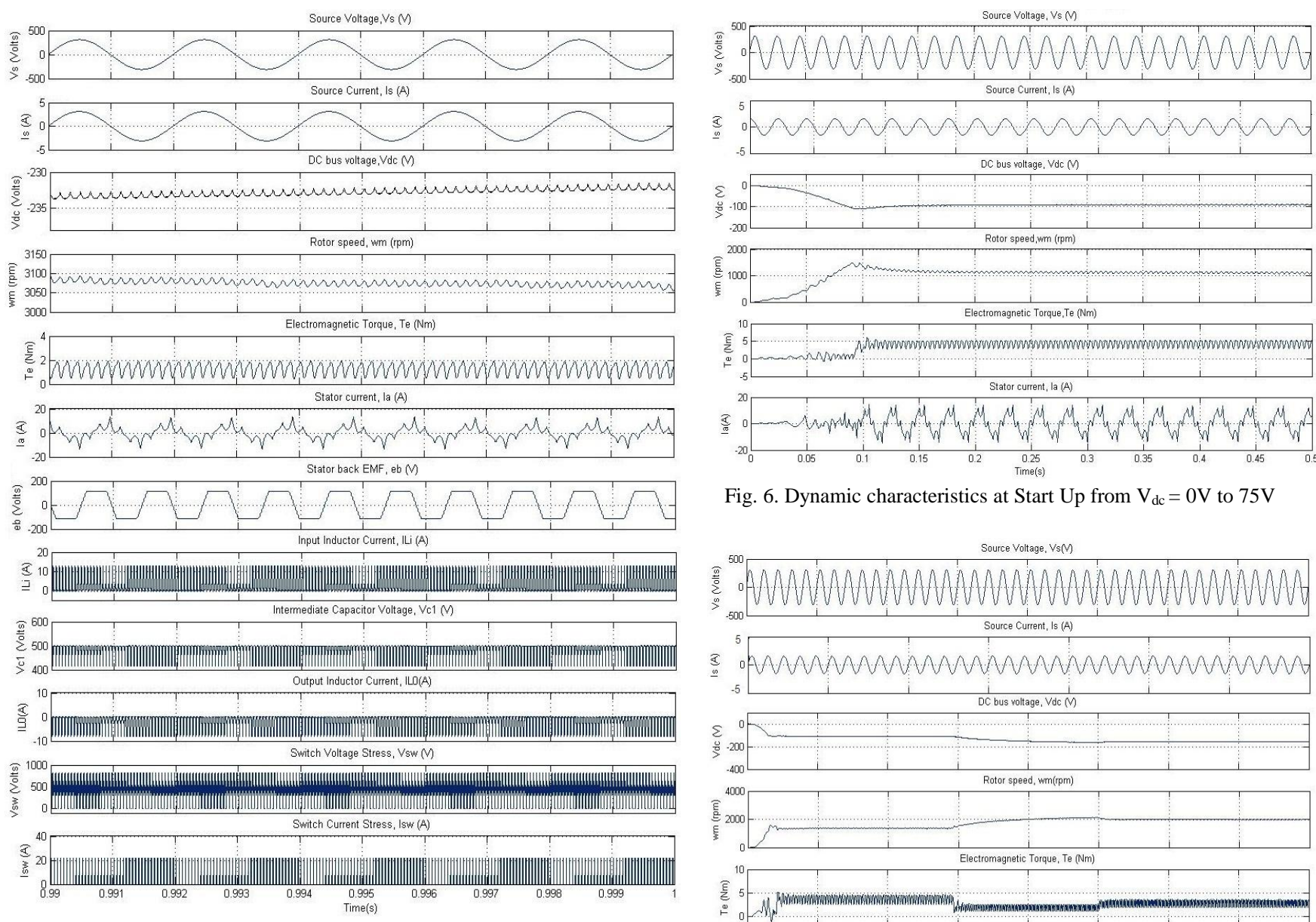

Fig. 6. Dynamic characteristics at Start $\mathrm{Up}$ from $\mathrm{V}_{\mathrm{dc}}=0 \mathrm{~V}$ to $75 \mathrm{~V}$

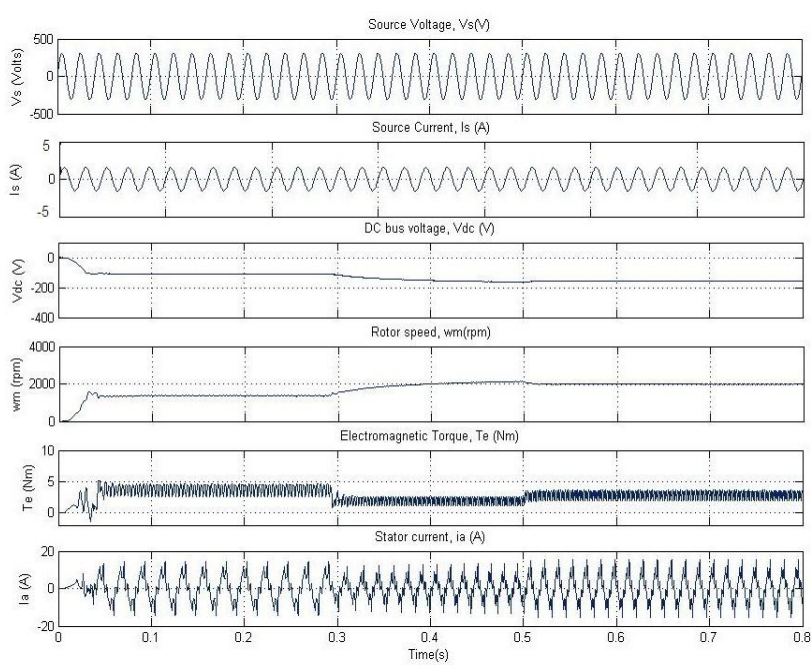

Fig.7. Dynamic characteristics for a step-rise in dc-link voltage from $\mathrm{V}_{\mathrm{dc}}=100 \mathrm{~V}$ to $150 \mathrm{~V}$.
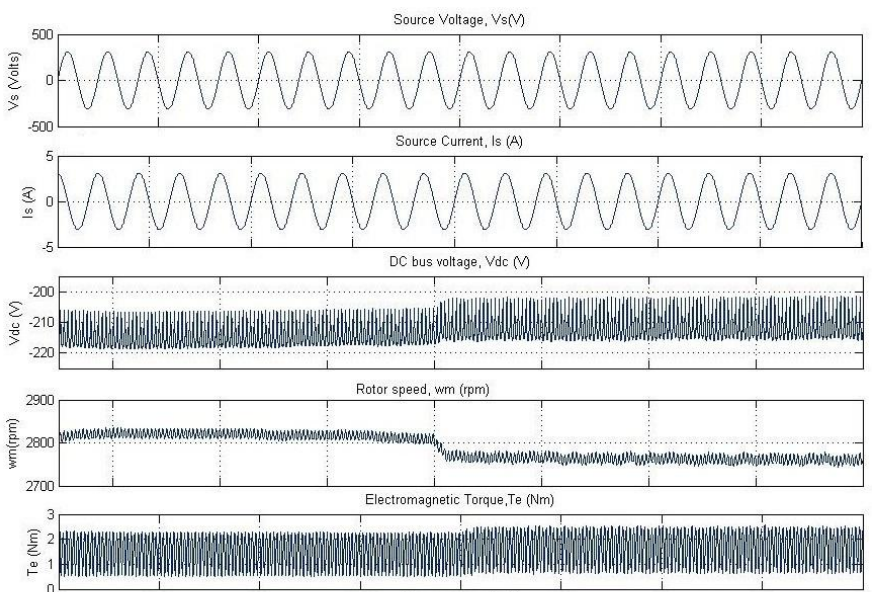

$\underbrace{20}_{0.2}$

Fig. 8. Dynamic characteristics for a step-rise in torque from $0.4 \mathrm{Nm}$ to $0.8 \mathrm{Nm}$

Published By:

Retrieval Number: A1185058119/19@BEIESP

DOI: 10.35940/ijrte.A1185.078219

Blue Eyes Intelligence Engineering

Journal Website: www.ijrte.org

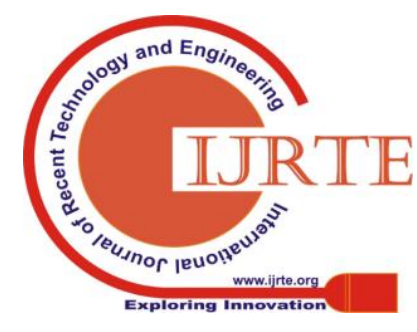




\section{CONCLUSION}

The performance evaluation of an Integrated, Single-stage converter-fed motor drive is introduced in this paper. Variable dc voltage method is employed for the drive speed control. Solid-state switches of the VSI are operated at the line frequency employing digital current commutation, thus minimizing their switching losses. Sensor-less Direct Back-EMF Zero-Crossing Detection scheme is utilized in developing the triggering pattern for the VSI switches. Overall efficiency of the drive is improved considerably due to reduction in the number of sensors, switching of the VSI switches at the fundamental frequency and Zero current turn-on of the converter switch. An inherent power factor correction and DC voltage control are achieved as the converter operates in D-DCM. The drive is analyzed for a comprehensive set of speeds and supply voltage variation and the PQ indices obtained are found to be inside the suggested ceilings of IEC 61000-3-2. This drive is recommended for use in low-power applications requiring vast speed control and uplifted power quality.

\section{REFERENCES}

1. V. Bist, B. Singh, "A Single Sensor, Single Switch Integrated PFC Buck-Boost Buck converter fed BLDC motor drive", Asian Power Electronics Journal, Vol.8, No.2, Nov. 2014, pp. 43-49.

2. V. Aishwarya, B. Jayanand, "Estimation and control of sensorless brushless dc motor drive using Extended Kalman Filter", In: 2016 International Conference on Circuit, Power and Computing Technologies (ICCPCT 2016), Nagarcoil, India, 2016 DOI: https://doi.org/10.1109/ICCPCT.2016.7530343

3. B. Singh, V. Bist, "Power Factor Correction (PFC) converters feeding brushless DC motor drive", International Journal of Engineering Science and Technology, Vol.7, No.3, 2015, pp.65-75.

4. B. Singh, S. Singh, "State of Art on Permanent Magnet Brushless DC Motor Drives”, J. Power Electron., Vol.9, No.1, Jan. 2009, pp.1-17.

5. D. Lenine, B. R. Reddy, S. V. Kumar, "Estimation of Speed and Rotor Position of BLDC Motor Using Extended Kalman Filter", Proc. IET-UK International Conference on Information \& Communication Technology in Electrical Sciences(ICTES 2007), Dr. M.G.R. University, Chennai, Tamil Nadu, India, Dec.20-22,2007,pp. 433-440.

6. B. Singh, S. Singh, "'Single-phase power factor controller topologies for permanent magnet brushless DC motor drives", IET Power Electron., Vol. 3, Issue 2, 2010, pp.147-175.

7. P. P. Acarnley, J. F. Watson, "Review of Position Sensorless Operation of Brushless Permanent Magnet Machines", IEEE Trans. Ind. Electron., Vol.53, No.2, Apr. 2006, pp. 352-362.

8. T.H. Kim, H.-W. Lee, M. Ehsani, "State of the art and future trends in Position Sensorless Brushless DC Motor/Generator Drives", Proc. $31^{\text {st }}$ Annual Conference of IEEE, IECON 2005, Industrial Electronics Society, 2005, pp.1718-725.

9. B. Singh, S. S. Murthy, B. P. Singh, M. Kumar, "Improved Power Quality converter fed permanent magnet AC motor for air-conditioning”, Electrical Power Systems Research, Elsevier, Vol.65, 2003, pp.239-245.

10. N. Matsui, "Sensorless PM Brushless DC Motor Drives", IEEE Trans. Ind. Electron., Vol.43, No.2, Apr. 1996, pp.300-308.

11. B. Singh, "Recent Advances in Permanent Magnet brushless DC Motors", Sadhana- Acad P. Eng. S., Vol.22, No. 6, Dec. 1996, pp.837-853.

12. D. Montesinos, S. Galceran, F. Blaabjerg, A. Sudria , O. Gomis, "Sensorless control of PM Synchronous motors and brushless dc motors - an overview and evaluation", Proc. 2005 European Conference on Power Electronics and Applications, Dresden, Germany, Sept. 2005, pp.1-10.

13. B. Terzic, M. Jadric. "Design and Implementation of the Extended Kalman Filter for the Speed and Rotor Position Estimation of Brushless DC Motor", IEEE Trans. Ind. Electron., Vol. 48, No.6, Dec. 2001, pp. 1065-1073, DOI: 10.1109/41.969385

14. P. Kettle, A. Murray \& F. Moynihan, "Sensorless control of a Brushless DC motor using Extended Kalman Estimator", Proc. PCIM'98 Intelligent Motion, USA, May 1998, pp.385-392. DOI:http://edge.rit.edu/edge/P13211/public/Senior\%20Design\%201/ Research/Motor\%20Controllers/121742246PCIM98_P.pdf
15. F. Hicham, R. Abdellatif, D. Mohamed, "Sensorless Control of the Trapezoidal BLDCM using Sliding Mode Observer. Proc. $16^{\text {th }}$ Triennial World Congress, Prague, Czech Republic, Elsevier IFAC Pub,Vol.38, pp.83-88, DOI: 10.3182/20050703-6-CZ-1902.00414

16. B. Singh, B.N. Singh, A. Chandra, K. Al-Haddad, A. Pandey, D.P. Kothari, "A Review of Single-Phase Improved Power Quality AC-DC Converters”, IEEE Trans. Ind. Electron., Vol.50, No.5, Oct.2003, pp.962-981.

17. V. Bist, B. Singh, "A PFC based Bridgeless Sheppard Taylor converter-fed brushless DC motor drive", Proc. 2014 Innovative Applications of Computational Intelligence on Power, Energy and Controls with their impact on Humanity (CIPECH), 2014, Ghaziabad, India, 2014, pp.262-267.

DOI: http://doi.org/10.1109/CIPECH.2014.7019083

18. V. Bist, B. Singh, "An Adjustable-Speed PFC Bridgeless Buck-Boost Converter-Fed BLDC Motor Drive", IEEE Trans. Ind. Electron. Vol.61, No.6, June 2014,pp.2665-2677.

19. O. Garcia, J. A. Cobos, R. Prieto, P. Alou, J. Uceda, "Single Phase power Factor Correction-A Survey", IEEE Trans. Power Electron. Vol.18, No.3, May 2013,pp.749-754.

20. B. Singh, V. Bist, "A PFC Based Switched-Capacitor Buck-Boost Converter fed BLDC Motor Drive”. In: 2013 Annual IEEE India Conference (INDICON), India, 2013. DOI: 10.1109/INDICON.2013.6725951

21. J. Merin, V. Aishwarya, "Sensorless brushless DC motor drive fed by Cuk converter", In: 2016 International Conference on Circuit, Power and Computing Technologies (ICCPCT), Nagarcoil, India, 2016, DOI https://doi.org/10.1109/ICCPCT.2016.7530108

22. V. Bist, B. Singh B., "PFC Cuk Converter-fed BLDC Motor Drive. IEEE Trans. Power Electron Vol.30, Feb. 2015, pp.871-888, DOI: 10.1109/TPEL.2014.2309706

23. S. Singh, B. Singh, "Power Factor Correction in Permanent Magnet Brushless DC Motor Drive using Single-Phase Cuk Converter. J. Eng. S. and Technol., Taylor's University 2010; Vol.5,pp.412-425,DOI http://jestec.taylors.edu.my/Vol\%205\%20Issue\%204\%20December\% 2010/Vol_5_4_412_425_Sanjeev.pdf

24. A. Lita, M. Cheles, "Sensorless BLDC control with Back-EMF filtering using a Majority Function, AN1160.” Microchip Technology Inc, 2008-2012, pp.1-24.

DOI: http://ww1.microchip.com/downloads/en/AppNotes/01160b.pdf

25. V. Bist, B. Singh, "Power factor correction in a brushless DC motor drive using an isolated-Luo converter", In: 2014 6th IEEE Power India International Conference (PIICON), 2014.

26. B. Singh, V. Bist. "A PFC based BLDC motor drive using a Bridgeless Zeta converter", Proc. IECON 2013 - 39th Annual Conference of the IEEE Industrial Electronics Society, 2013, pp.2553-2558.

27. V. Bist, B. Singh. "A Unity Power Factor Bridgeless Isolated Cuk Converter-Fed Brushless DC Motor Drive", IEEE Trans. Ind. Electron., Vol. 62, No. 7, July 2015, pp.4118-4129.

\section{AUTHORS PROFILE}

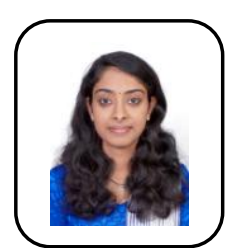

Aishwarya V. received her B.Tech degree in the year 2006 in Electrical \& Electronics Engineering from Toc H Institute of Science \& Technology and M.Tech degree in Power Electronics from Govt. Engg. College, Trichur in 2010. She is currently working towards the Ph.D. degree in Electrical Engineering at the Kerala Technological University, Trivandrum. Her major interests include modelling, control and analysis of power electronic circuits and industrial drives.

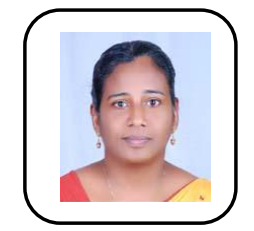

Gnana Sheela K. received her Ph.D in Information and Communication from Anna University, Chennai. She is working as a Professor, ECE Department, Toc H Institute of Science and Technology. She has published more than 40 international journal papers. She is reviewer, editor in various international papers. Also she is a life member of ISTE. 